\title{
Investigation of the flow between a PV panel and building's outer skin comprising a naturally ventilated BIPV system
}

\author{
Rafaela A. Agathokleous, Soteris A. Kalogirou \\ Cyprus University of Technology, Limassol, Cyprus
}

\begin{abstract}
The installation of BIPV systems should be able to circulate cooling air at the back side of the PV panels in order to maintain high electrical conversion efficiency of the PV panels and avoid building overheating. This paper is focused on the understanding of the airflow between the building's façade and the PV panel in naturally ventilated Building Integrated Photovoltaic (BIPV) panels. Flow visualisation measurements, hot wire anemometer measurements as well as temperature measurements were performed. These were performed in laboratory controlled environmental conditions under constant artificial solar radiation. These results are supported also with CFD simulation results. It is shown that the openings of the duct have an important role on the thermal behaviour of the system, and buoyancy effect resulted to velocities of $0.3 \mathrm{~m} / \mathrm{s}$. The optimum configuration is finally tested at building level to a demonstration building at Mons, Belgium, with very satisfactory results.
\end{abstract}

\section{Introduction}

The investigation of natural convection which develops in vertical open channels is of major importance since it is found in many applications in the last years such as the double skin facades and naturally ventilated building integrated photovoltaic (BIPV) systems. The use of the latter has increased recently because of the promotion made in various countries for the implementation of Renewable Energy Systems (RES) due to the need of the countries to reduce their energy consumption and emissions. Solar energy systems are the easiest among other RES for building installations and especially BIPV systems where the PV panels are part of the building's construction. The double skin BIPV systems are part of the building's construction since PV panels replace conventional construction materials of the building's envelope, forming at the same time a construction element which is also an on-site energy producer.

The installation of BIPV systems should be able to circulate cooling air at the back side of the PV panels in order to maintain high electrical conversion efficiency of the PV panels and avoid building overheating. The ventilation of the back side of the PV panels can be either natural or forced by external means such as fans. When the system is mechanically ventilated, the velocity of the air in the duct between the PVs and the external part of the building is known and controlled. In the case of natural ventilation, the air flow is depended on buoyancy forces where the air becomes less dense when is heated by the direct contact with the PV. Accordingly, mechanically ventilated systems are more convenient to cool the PV panels although they have various disadvantages over the naturally ventilated systems e.g. noise from the fans, extra required energy for the fans, maintenance, and difficult installation.

Thus, naturally ventilated systems are preferred and examined in this paper. The considered concept and the related research topic is very important to the contribution of the EU directives for the wider adoption of the renewable energy systems, through the improvement of the BIPV technology with natural ventilation. It is believed that the advantages of the naturally ventilated systems can be maximized when correct design is done, to allow efficient PV cooling.

This work presents an extensive research which is carried out to describe the behaviour of the air flow in BIPV systems. This is done with flow visualization measurements, temperature measurements and anemometry measurements, CFD simulation and TRNSYS simulation. The last is performed using the knowledge and values estimated from the other analyses. It is based on a real case BIPV system and the results referring on the performance of the system and the temperature of the PV panels are compared with real monitoring data recorded on site.

There are various studies made on the heat transfer in natural convection conditions of vertical open channels, and the chimney effect, but as concluded by Agathokleous and Kalogirou (2016) very few studies are made on the naturally ventilated BIPV systems.

The studies by Fossa et al. (2008); Gaillard et al. (2014), consider mainly the performance investigation and flow analysis. These are experimentally investigated by Kaiser et al. (2014); Lee et al. (2014); Ranjan et al. (2008); Zogou and Stapountzis (2011), and with simulations by Roeleveld et al. (2015); Yoo (2011); Zhang et al. (2017). There are studies focused on BIPVs on a building level as the ones presented by Kyritsis et al. (2017); Mei et al. (2003); Wang et al. (2006) or as an individual system Brinkworth (2000); Brinkworth et al. (1997); Lau et al. (2012); Yang and Athienitis (2015). Mei et al. (2003), presented a building level investigation based on the thermal characteristics of the building, Wang et al. (2006) presented the influence of the BIPV systems on the 
heating and cooling loads, and Kyritsis et al. (2017) focused on the energy coverage by the BIPV.

Regarding particularly the effect of air flow in the duct of the naturally ventilated BIPV systems is very little investigated. Natural flow involving low velocities is sensitive to environmental conditions and thus difficult to measure. The unsteady nature of this flow does not depend only on the thermal behaviour and kinematic activity of the air duct, but also to the pressure and temperature conditions outside the channel.

Zogou and Stapountzis (2012) investigated the flow and heat transfer inside a PV/T collector for building application, for 3 cases, using a low capacity fan, a high capacity fan and buoyancy flow created naturally. The system investigated by Zogou and Stapountzis (2012) considering natural flow due to buoyancy effect is very similar to a naturally ventilated BIPV system where natural air flow occurs in the air gap between the PV panel and a second skin due to the increase of the air's temperature. It was concluded that for the buoyancy driven air case the flow belongs in the transitional flow regime, with air velocity of $0.1 \mathrm{~m} / \mathrm{s}$. The flow investigation was done experimentally with flow visualisation using particle image velocimetry (PIV) technique, as well as with hot wire anemometry analysis.

Sanvicente et al. (2013) investigated the transitional natural convection flow in an open channel experimentally. A double skin PV configuration is tested with different heating configurations. This study was mainly focused on the kinematic characteristics of the flow and convective heat transfer at the heated wall. It was concluded that the flow is neither turbulent nor purely laminar.

Sanjuan et al. carried out an experimental analysis with a 2D PIV technique on the natural convection in open joint ventilated facades (OJVF), paying attention specifically at the ventilation effect through the joints. It was concluded that the heating slabs of the front surface of the tested duct produce ventilation flow in the cavity, the velocity of the air in the cavity increases with the buoyancy forces e.g. temperature differences, as well as that the air enters the cavity from the lower joints and exits from the upper ones. Sanjuan et al. (2011b) also developed a simulation model validated with the experimental data from Sanjuan et al. (2011a). The results from the PIV measurements performed in Sanjuan et al. (2011a) are compared with simulation results from different turbulence and radiation models applied on a three dimensional model. The results showed that ventilation air flow inside the cavity is enhanced by incident radiation as well as by the height of the façade.

Tkachenko et al. (2016) investigated numerically and experimentally the unsteady natural convection in a nonuniformly heated vertical open-ended channel forming a double skin BIPV system. It was concluded that staggered arrangement of PV panels produces higher mass flow rate of the air in the channel.

\section{Experimental Setup}

The experimental procedures are carried out in indoor laboratory conditions with the use of a solar simulator to provide artificial solar radiation. The laboratory has controlled conditions without external disturbances to affect the experimental procedures.

A custom made experimental BIPV apparatus is used in the experimental procedures, consisting of a PV panel, two plexiglass sheets and a wooden back wall as shown in Figure 1. The polycrystalline PV panel used is $1.64 \mathrm{~m}$ long, $0.992 \mathrm{~m}$ wide and $0.004 \mathrm{~m}$ thick, the plexiglass sheets are $1.64 \mathrm{~m}$ long, $0.1 \mathrm{~m}$ wide and $0.01 \mathrm{~m}$ thick and the back wooden wall is $1.64 \mathrm{~m}$ long, $0.992 \mathrm{~m}$ wide and $0.1 \mathrm{~m}$ thick. The two plexiglass sheets, the PV panel and the wall, create a rectangular duct, open at the bottom and the top for fresh air circulation to provide PV cooling to avoid efficiency loss. The surface of the PV panel is subjected to constant incident radiation from the solar simulator of $1000 \mathrm{~W} / \mathrm{m}^{2}$ for 3 hours in each experimental procedure.

The air circulation in the formed duct occurs due to the chimney effect. When the temperature of the PV panel surface increases, the air behind the PV panel gets hotter as well due to the direct contact with the hot surface of the PV panel. Thus, the air becomes less dense and moves upwards until it exits the duct from the top opening. Simultaneously fresh air is sucked in the duct from the bottom opening.

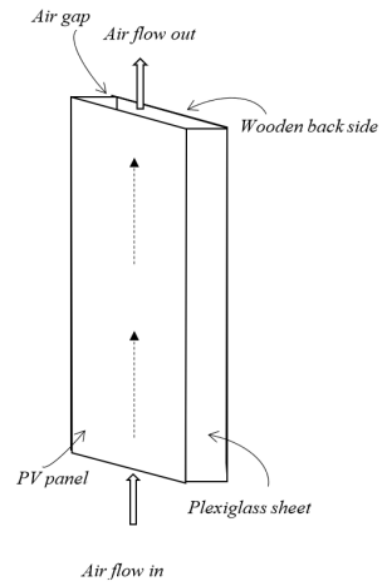

Figure 1: Schematic representation of the vertical naturally ventilated BIPV system tested in the laboratory under controlled conditions and constant artificial solar radiation.

\section{Flow Visualisation}

Figure 2 shows a schematic representation of the flow visualisation technique employed. The flow visualisation was performed after the system had reached steady state conditions. A green laser with a rotating mirror is employed to produce a plain sheet of light as shown in Figure 2. The laser sheet lights-up a vertical section of the channel, parallel to the plexiglass sheets, in the middle of the duct. 
A smoke fog machine (Chauvet Hurricane 700) is employed to produce smoke in the laboratory as shown in Figure 2. In order to avoid forced movements of the particles in the air duct, the smoke machine was placed at a 2-m distance from the experimental apparatus and the injection of the smoke particles was done in the whole laboratory room to ensure that there is no interference with the natural convection in the gap.

The smoke passes through the air duct and moves upwards with the flow. The movement of the smoke is captured with the use of a commercial high definition (HD) camera placed next to the plexiglass sheet, outside the channel. The camera produces high definition video files and photo clips as well. The time lapse between each clip is $0.1 \mathrm{~s}$.

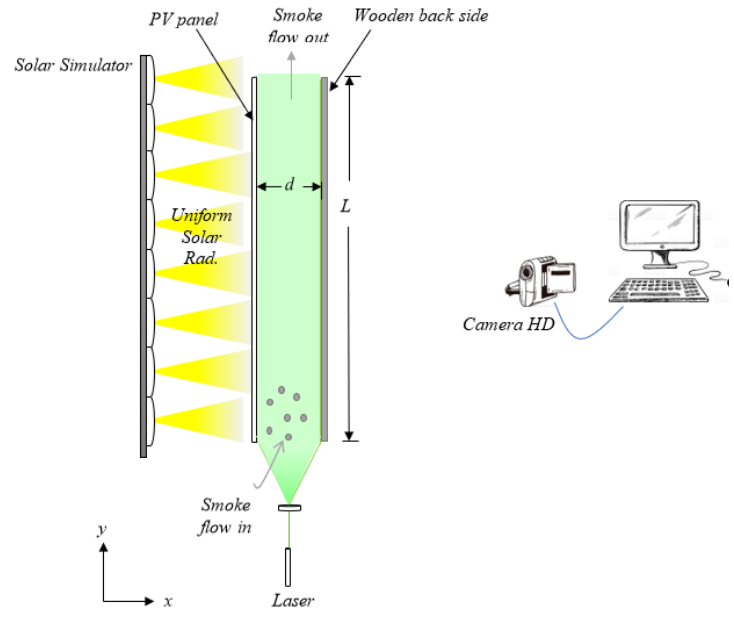

Figure 2: $x-z$ section of the schematic representation of the flow visualisation experimental procedure.

The flow visualisation experiments show that the flow is neither turbulent nor purely laminar at the lower part of the channel. The results indicate that the flow is in the transition flow regime. It can be observed that, the effect of the flow entrance is significant, but no clear turbulence flow appears.

Various flow patterns are visible in the clips that move vertically upwards following the main flow, at average velocity of $0.28-0.32 \mathrm{~m} / \mathrm{s}$. The fluid velocity is calculated using the camera timing $(\Delta t)$ and the smoke particles displacement.

In order to see clearly the type of the air flow, the camera was moved upwards to capture the flow at a higher level of the channel in order to avoid the effect of the flow entrance. From these clips, the flow is shown to be laminar, with air velocity from 0.28 to $0.3 \mathrm{~m} / \mathrm{s}$.

\section{Hot Wire Anemometer Measurements}

The HD 2303.0 hot wire anemometer from Delta Ohm is used with the probes AP 471 S2 to measure low air velocities with two decimals accuracy. The HD 2303.0 is a portable instrument with an LCD display. The AP 471 S2 probe can adjust its length with a telescopic shaft to $800 \mathrm{~mm}$ and this gives us the ability to measure at any depth in the air gap. The probe diameter on the measurement area is $8 \mathrm{~mm}$.
The experimental representation is shown in Figure 3, which shows the section of the air channel and the three positions where the hot wire anemometer probes are placed to perform air velocity measurements.

The probes are inserted in the channel from drilled holes at different heights on the plexiglass sheet at $y 1=0.1 \mathrm{~m}$, $\mathrm{y} 2=0.72 \mathrm{~m}$ and $\mathrm{y} 3=1.44 \mathrm{~m}$. The measurements were performed along the centreline in the middle of the air gap in $d / 2$. A total of 30 measurements were recorded in every measurement in order to establish stable and correct air velocity.

The temperature distribution of the system is recorded during the experimental procedures as well. A total of 9 thermocouples were placed at the back side of the PV panel to measure the temperature of the PV panel, 6 thermocouples to measure the temperature of the air in the air gap in y1 and y3, and 3 thermocouples to measure the temperature at the outer side of the wooden back wall. All thermocouples were connected with data loggers recording during the experimental procedures with time interval of 1 minute.

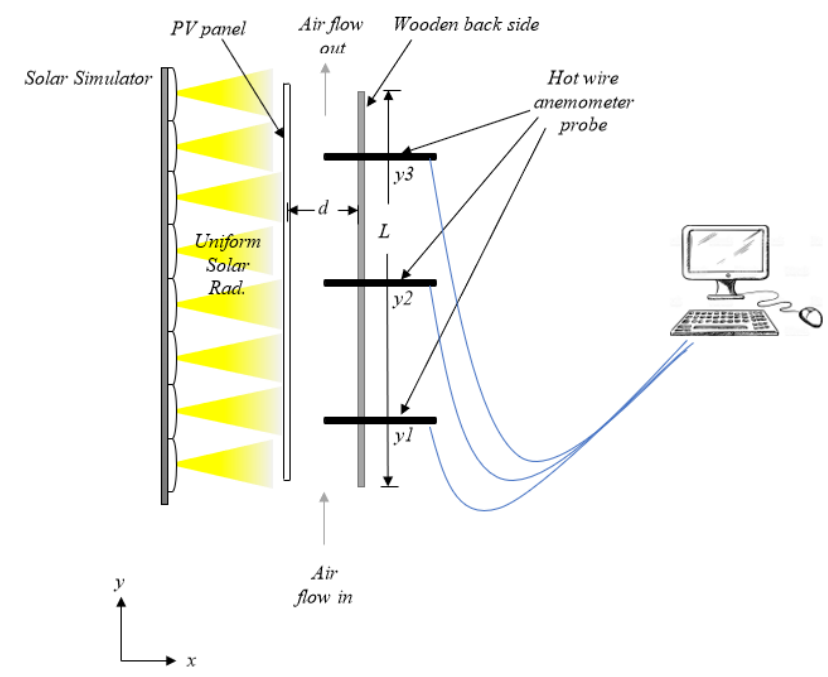

Figure 3: The schematic representation of the hot wire anemometry experimental procedure.

The temperatures of the ambient air as well as the air near the bottom opening of the duct and near the top opening are shown in Figure 4. Figure 5 shows the velocity of the air in the middle of the air gap at $\mathrm{d} / 2$ measured at $\mathrm{y} 2$ level. As can be seen, after 40 minutes of exposure time, where the temperature of the system was almost stable, the air velocity varies between $0.30-0.34 \mathrm{~m} / \mathrm{s}$.

\section{Unit Level Simulation}

For the simulation of the system on the apparatus size, COMSOL Multiphysics software was used.

The geometry of the BIPV model is shown in Figure 6. The model is built in the same dimensions as the experimental apparatus presented in the previous chapter and consists of three volumes separated in three domains, the PV panel, the air and the wall. The dimensions of the PV panel, air gap and wall are 1642 x 992 x 4 mm, 1642 x 992 x 100 mm and 1642 x 992 x 200 mm respectively. 


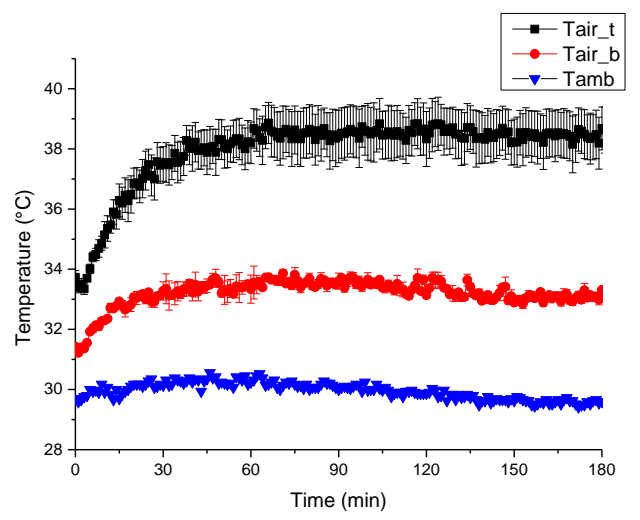

Figure 4: The temperature of the ambient air in the laboratory and the temperature of the air in the duct in heights $y 1$ and $y 3$.

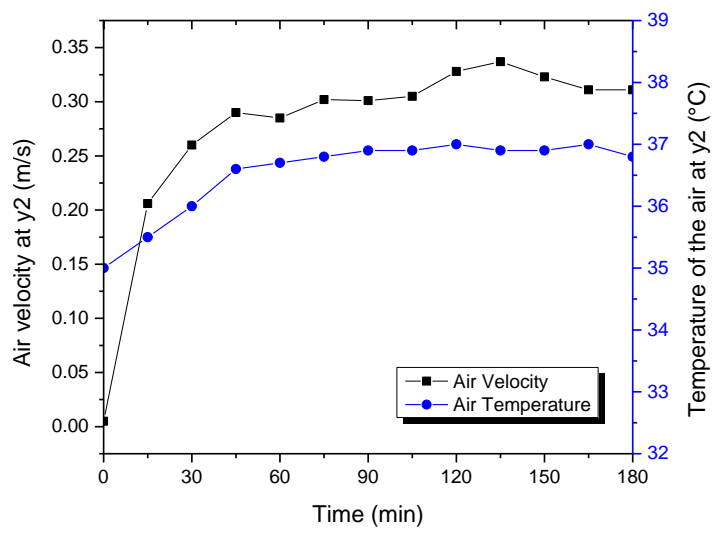

Figure 5: The air velocity and average air temperature in the height $y 2$.

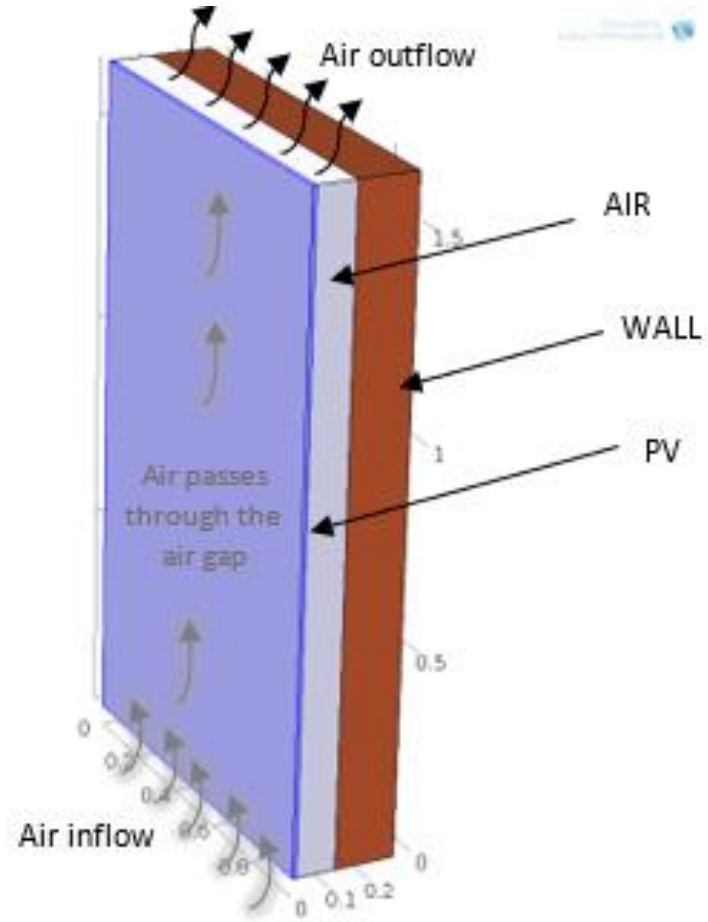

Figure 6: The 3D model in COMSOL showing the PV panel, the air gap and wall of the building.
Figure 7 shows the heat transfer mechanisms of the system in a resistance circuit form.

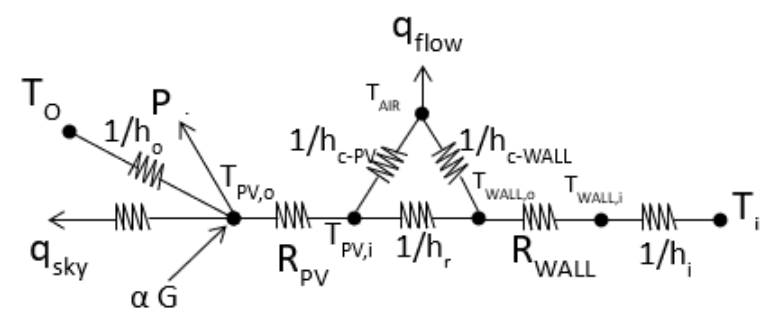

Figure 7:Circuit of the thermal resistances and heat transfer mechanisms in a Building Integrated Photovoltaic Façade.

To formulate the heat exchange process for a fluid flowing between the PV panel and the building's wall, time dependent partial heat transfer differential equations (PDEs) are used. The following three equations were solved for the three domains of the model PV, air and wall, considering the heat transfer solver of COMSOL software:

$$
\begin{gathered}
\rho C_{p} \frac{\partial T_{P V}}{\partial t}=\nabla\left(k \nabla T_{P V}\right) \\
\rho C_{p} \frac{\partial T_{\text {air }}}{\partial t}+\rho C_{p} u \nabla T_{\text {air }}=\nabla\left(k \nabla T_{\text {air }}\right) \\
\rho C_{p} \frac{\partial T_{\text {wall }}}{\partial t}=\nabla\left(k \nabla T_{\text {wall }}\right)
\end{gathered}
$$

The heat transfer interfaces use Fourier's law of heat conduction, which states that the conductive heat flux $\dot{q}$ is proportional to the temperature gradient:

$$
-k \frac{\partial T}{\partial x}=\dot{q}
$$

The convection is set to be natural and it is considered to exist at the front of the PV, the back of the PV, the front of the wall and the back of the wall.

$$
\dot{Q}=h\left(T_{s}-T_{\infty}\right)
$$

Where $h$ is the convective heat transfer coefficient $\left(\mathrm{W} / \mathrm{m}^{2} \mathrm{~K}\right), T_{s}$ is the surface temperature $\left({ }^{\circ} \mathrm{C}\right)$ and $T_{\infty}$ the ambient air temperature $\left({ }^{\circ} \mathrm{C}\right)$.

The radiation exchange at the outer of the PV panel and the inner of the wall is defined by the following equation, using the appropriate properties and parameters of each domain (PV or wall).

$$
\dot{Q}=\varepsilon \sigma\left(T_{s}{ }^{4}-T_{\text {surr }}{ }^{4}\right)
$$

Where $e$ is the emissivity of the surface, $\sigma$ is the Stefan Boltzmann constant and $T_{\text {surr }}$ is the temperarure of the surrounding surfaces $\left({ }^{\circ} \mathrm{C}\right)$.

The convective heat transfer coefficients (CHTC) were estimated each time with the appropriate equation because the conditions in each section of the system are not the same and the coefficients cannot be assumed to be the same everywhere or constant from the bottom to top of the system. Regarding the convective heat transfer 
coefficient in the duct, the following correlation proposed by Agathokleous and Kalogirou (2018a) was used:

$$
N u=1.23\left(R a^{*}(d / L)\right)^{0.168}
$$

Where the modified Rayleigh number $R a^{*}$ is given by:

$$
R a^{*}=\frac{g \beta d^{4} \dot{q}_{c} \rho C_{p}}{v k^{2}}
$$

Where $d$ is the size of the air gap (m), $L$ is the height of the duct $(\mathrm{m}), v(\mathrm{~kg} / \mathrm{m} \mathrm{s})$ is the kinematic viscosity of air (equal to $\mu / \rho), k$ is the thermal conductivity of air $(\mathrm{W} / \mathrm{mK})$.

Accordingly, the CHTC in the air gap can be estimated by the following formula considering $D_{h}$ the hydraulic diameter of the duct which is $D_{h}=4 A_{c} / p$ :

$$
N u=\frac{h_{\text {gap }} D_{h}}{k}
$$

Due to the different heat transfer conditions in the various parts of the system, not all the CHTC are estimated with the use of Equation (7). Thus, the CHTC in the front surface of the PV and the back surface of the wall (facing indoors), are estimated by the use of empirical $\mathrm{Nu}$ number equation given by Churchill and Chu (1975) for natural convection over vertical plates:

$$
=\left\{0.825+\frac{0.387 R a_{L}^{1 / 6}}{\left[1+(0.492 / P r)^{9 / 16}\right]^{8 / 27}}\right\}^{2}
$$

Where

$$
R a_{L}=\frac{g \beta\left(T_{s}-T_{\infty}\right) L_{c}{ }^{3}}{v^{2}} \operatorname{Pr}
$$

Where $L_{c}$ is the characteristic length of the geometry (m), in this case the height of the $\mathrm{PV}, \beta$ is the volumetric coefficient of thermal expansion $(1 / \mathrm{K})$, and $P r$ is the Prandlt number.

In this section, the validated model by Agathokleous and Kalogirou (2018b) is used to investigate the effect of the air velocity in the temperature distribution of the system. The model is tested under various air velocities from 0.05 $\mathrm{m} / \mathrm{s}$ to $3 \mathrm{~m} / \mathrm{s}$ at constant air gap of $10 \mathrm{~cm}$.

Real weather data are imported in the mathematical model with equations. The idea is to run the simulations in a typical summer day and observe the effect of the air velocity in the air gap between the two skins on the temperature distribution of the system. The equations for radiation and ambient temperature were derived in Excel, from the weather data extracted from the Typical Meteorological Data (TMY) files of Nicosia, Cyprus, using TRNSYS software. Then data are imported in COMSOL in the form of equations depended on time. The solar radiation data used, were considering east oriented surface, at the location of Nicosia Cyprus, vertical position. For these conditions, the effective hours were from 5:00 am to 13:00 pm and thus, the simulations were carried out within this time period. Solar radiation data and ambient air temperature data used are shown in Figure 8.
The simulations were carried out multiple times considering various velocities from $0.05 \mathrm{~m} / \mathrm{s}$ to $3 \mathrm{~m} / \mathrm{s}$ at constant air gap of $0.1 \mathrm{~m}$. It should be noted that the initial temperature value of all boundaries for all parts of the system is set to ambient temperature.

Figure 9 shows the temperature at the boundary at the Oinner surface of the PV which faces the air gap, from hours 5:00 to 13:00 for all the tested velocities. As can be observed, the higher the air velocity, the lower is the temperature distribution of the panel's surface. The faster the air flows into the duct, the more heated air is removed from the duct which is created due to the hot surface of the PV panel.

When the air velocity in the duct is the lowest, the maximum average temperature at the inner side is $76^{\circ} \mathrm{C}$. It is important also to observe the point at which the maximum temperatures occur. As can be seen, this point is around 8:00 o'clock where the solar radiation is near its maximum, and the ambient temperature increases.

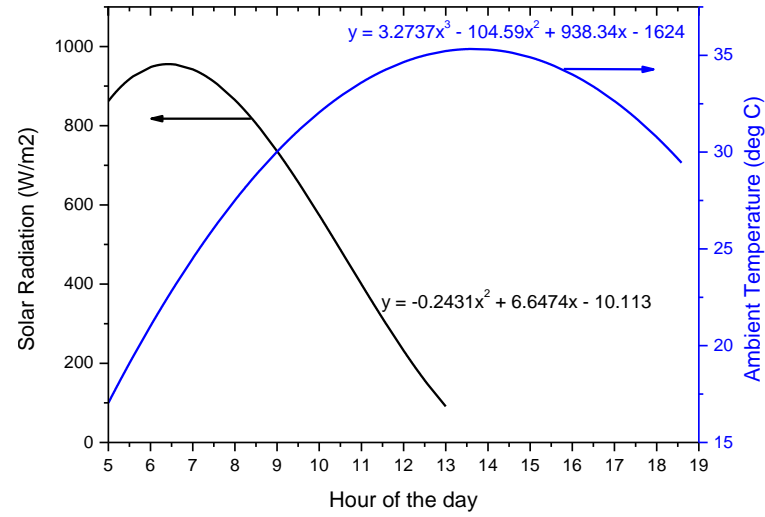

Figure 8: Solar radiation on vertical surface oriented east, and the temperature variation during a typical day in June in Cyprus.

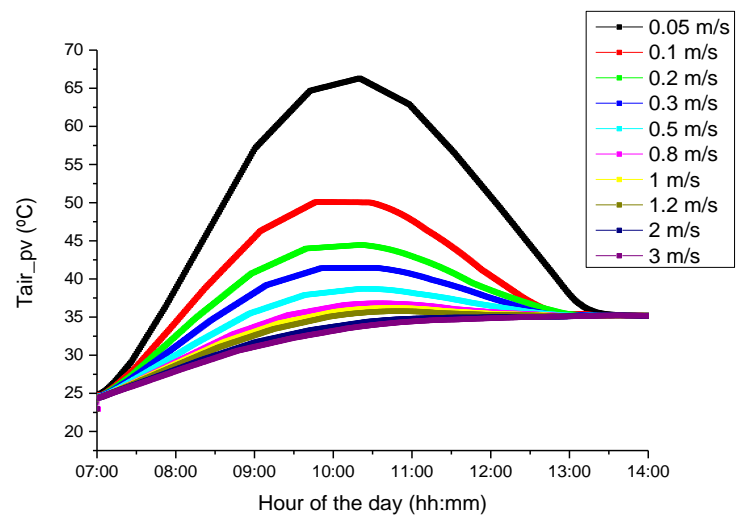

Figure 9: Temperature at the inner boundary surface of the PV facing the air gap.

It is also important to observe the temperature of the flowing air in the duct, since this is an important parameter that affects the temperature distribution on the system's surfaces. As can be seen in Figure 10 the graph has the same trend with the PV panel's temperature distribution showed earlier and it is affected from the air velocity with the same way. 


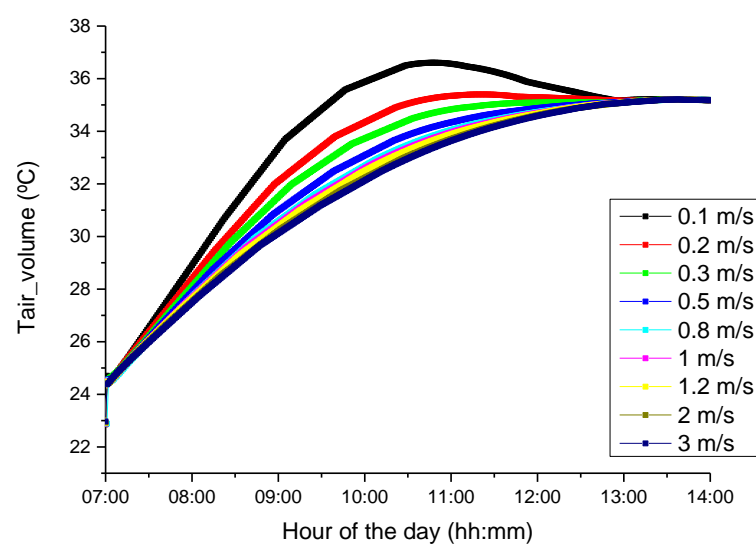

Figure 10: Average temperature of the air in the air gap for all the tested velocities.

\section{Building Level Simulation}

The knowledge gained from the analyses above, were finally used to suggest sizing and design of a roof BIPV system of a house in Mons, Belgium. This work is developed under the BFIRST (Building integrated Fibre Reinforced Solar Technology) EU FP7 funded project.

Taking into consideration the investigation presented so far, an air gap of $10 \mathrm{~cm}$ was recommended with natural ventilation. As proved earlier, a naturally ventilated air gap of $10 \mathrm{~cm}$ is adequate to keep the performance of the system in normal levels in a typical summer day in Cyprus and thus the same conditions would work efficiently in Belgium as well where the climate is cooler.

To make sure this assumption will work in real Belgium weather conditions, a BIPV simulation model in TRNSYS was developed prior to the installation of the BIPV system to examine the effectiveness of the proposed design of the system regarding the size of the air gap and the type of ventilation. It is very important to predict the performance and thermal behavior of the system before the installation because it will help the installers and the engineers to make changes to optimize the installation. Apart from the PV surface temperature and the energy production of the system, the developed model can estimate the mean temperature of the air in the duct between the PV panels and the roof's substructure, the temperature of the air in the outlet, the thermal efficiency of the system, the convective and radiative loses, etc. The main components of the model used are Type 566 and Type 109. Type 566 from the Electrical Library of TRNSYS is used to represent the BIPV system, and Type 109 the weather data. A simulation is carried out for one year, with one-hour time step, considering the real dimensions of the system, Inclination angle of $40^{\circ}$ and orientation of 10 degrees from south.

For the estimation of the convective heat transfer coefficients in the building level simulation model, correlation (10) was used for the internal roof space while equation (7) for the space between the PV panels and the roof substructure. Since the correlation (7) was obtained for vertical BIPV demonstration, here in this analysis it is assumed that the sloped roof will have similar behaviour and thus the same correlation for the convective heat transfer coefficients is used. The validity of this assumption will be checked from the comparison of the temperature of the PV panels between the monitoring and simulations results.

The simulation is carried out for one year with the use of real hourly weather data from TMY file of Brussels, Belgium. After one-year operation of the system, the monitoring data were compared to the simulation data.

The roof is firstly covered with thermal insulation and a wooden structure. Then, aluminium profiles are installed on the wooden structure to fix the PVs. From top to the bottom the modules overlap, to form one large continuous PV surface to cover all the roof's area. From left to right there are no joints in between the panels. Although earlier it was proposed to leave openings between the panels when the application has a large height, in this case it was not possible to install the panels with open joints in between because it is a roof installation and the aim was to keep the picture of the roof as much as closer to normal tiles and avoid rain water leakage to the insulation. Thus, a continuous PV surface is formed and the air duct is ventilated with bottom and top opening as shown in Figure 11. Additionally, the continuous surface of the PV panels in this case is not a major problem because Belgium has a cold climate and it is easier to avoid overheating by leaving an optimum air gap size and openings at the bottom and top of the system only.

Considering the size of the RS modules and the size of the two roof parts, a total of 57 RS modules are installed as shown in Figure 12, 49 on the big part of the roof and 8 at the small part. The total installed nominal power of the $\mathrm{PV}$ plant is $7.01 \mathrm{kWp}$. The residential house is connected to the electric grid using a $3 \times 230 \mathrm{~V}$ connection of 12.7 $\operatorname{kVA}(30 \mathrm{~A})$.

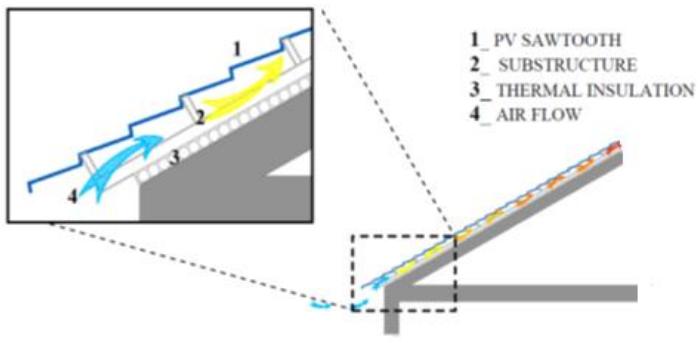

Figure 11: The roof structure showing the way of the air flow behind the PV panels.

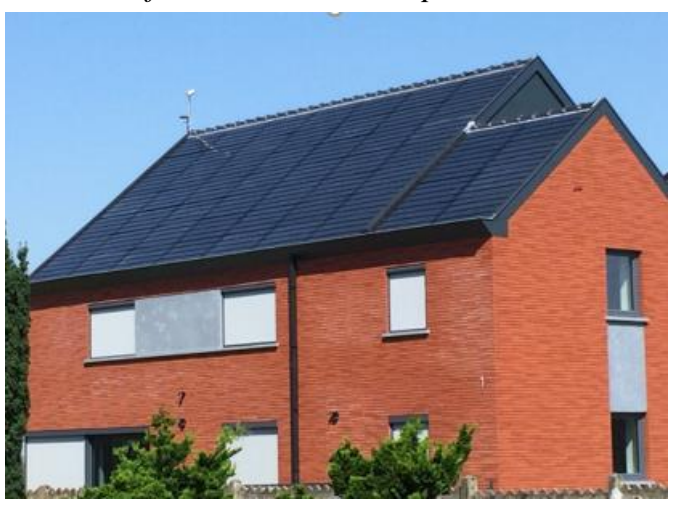

Figure 12: The 57 RS modules on the roof of the demonstration building. 
Overall, there is a good agreement between the simulation and measured monitoring data. The total numbers and the estimated percentage differences are shown in Table 1. The annual estimated energy production from the system is very close to the measured one. However, in monthly, daily or hourly based data the amount of energy is different. This is because the TMY data are usually used for mean annual performance evaluation of thermal systems and does not necessarily coincide with the actual weather data for particular days. The percentage relative error (PRE) between the predicted and measured energy production of the system for one year is $1.46 \%$ which is very small. Higher PRE appears for the maximum PV temperature values which is due to the fact that simulation predicted higher temperature because the correlation used to estimate the convective heat transfer coefficients in the air gap was based on vertical system. However, even with this assumption, a PRE of $4.47 \%$ is considered acceptable for building level simulation, as the purpose of carrying out this simulation was to see the annual performance of the system before its final design and installation.

Table 1:Comparison between the simulation and measured data and the estimated percentage relative error (PRE).

\begin{tabular}{|l|c|c|c|}
\hline & Simulation & Measured & PRE \\
\hline $\begin{array}{l}\text { 1 year energy } \\
\text { production }\end{array}$ & $\begin{array}{c}9507.40 \\
\mathrm{kWh}\end{array}$ & $\begin{array}{c}9648.2 \\
\mathrm{kWh}\end{array}$ & $1.46 \%$ \\
\hline $\begin{array}{l}\text { Maximum PV } \\
\text { Temperature }\end{array}$ & $67^{\circ} \mathrm{C}$ & $64^{\circ} \mathrm{C}$ & $4.47 \%$ \\
\hline $\begin{array}{l}\text { Maximum } \\
\text { Outlet Air } \\
\text { Temperature }\end{array}$ & $36.7^{\circ} \mathrm{C}$ & $36.1^{\circ} \mathrm{C}$ & $1.66 \%$ \\
\hline $\begin{array}{l}\text { Most } \\
\text { productive } \\
\text { month }\end{array}$ & July & July & - \\
\hline $\begin{array}{l}\text { Less } \\
\text { Productive } \\
\text { month }\end{array}$ & December & February & - \\
\hline
\end{tabular}

\section{Conclusion}

In this study, the air flow of the air duct of a naturally ventilated BIPV system is tested. Flow visualization measurements were carried out, as well as, hot wire anemometer measurements. The effect of the air velocity in the air gap is investigated with CFD simulations and then, a TRNSYS model was developed to predict the performance of a real scale roof BIPV system in Belgium.

The most important conclusions are summarized below:

- The air gap plays an important role in the performance of the BIPV since it affects the temperature distribution of the system.

- Buoyancy effect occurs in the system as proved by the indoor experiments. The average air velocity measured by hot wire anemometry is $0.3-0.34 \mathrm{~m} / \mathrm{s}$ while from flow visualisation was $0.28-0.32 \mathrm{~m} / \mathrm{s}$.

- The higher the air velocity in the duct, the lower is the temperature of the various parts of the system.

- Building simulation model results showed good agreement with real monitoring measurements regarding the annual energy production of the system and the predicted maximum temperature of the PV panels, even with the assumption that the convective heat transfer coefficients for the vertical system apply also to the sloped system tested.

\section{Acknowledgement}

Part of this work is carried out under the research program Building-integrated fibre-reinforced solar technology (BFirst), funded by the EU Seventh Framework Programme FP7/2007-2013, under grant agreement $n^{\circ}$ 296016.

\section{Nomenclature}

$\begin{array}{ll}\text { BFIRST } & \text { Building fibre reinforced solar technology } \\ \text { BIPV } & \text { Building integrated photovoltaic } \\ \text { CFD } & \text { Computational fluid dynamics } \\ \text { CHTC } & \text { Convective heat transfer coefficients } \\ \text { EU } & \text { European Union } \\ \text { OJVF } & \text { Open joint ventilated façade } \\ \text { PV } & \text { Photovoltaic } \\ \text { PIV } & \text { Particle image velocimetry } \\ \text { PV/T } & \text { Photovoltaic/thermal } \\ \text { PRE } & \text { Partial relative error } \\ \text { RES } & \text { Renewable energy systems } \\ \text { TMY } & \text { Typical meteorological year } \\ \text { TRNSYS } & \text { Transient simulation system }\end{array}$

\section{References}

Agathokleous, R.A., Kalogirou, S.A., (2016). Double skin facades (DSF) and building integrated photovoltaics (BIPV): A review of configurations and heat transfer characteristics. Renew. Energy 89, 743-756.

Agathokleous, R.A., Kalogirou, S.A., (2018a). Part I: Thermal analysis of naturally ventilated BIPV system: Experimental investigation and convective heat transfer coefficients estimation. Sol. Energy 169, 673681.

Agathokleous, R.A., Kalogirou, S.A., (2018b). Part II: Thermal analysis of naturally ventilated BIPV system: Modeling and Simulation. Sol. Energy 169, 682-691.

Brinkworth, B.., (2000). Estimation of flow and heat transfer for the design of PV cooling ducts. Sol. Energy 69, 413-420.

Brinkworth, B.., Cross, B.., Marshall, R.., Yang, H., (1997). Thermal regulation of photovoltaic cladding. Sol. Energy 61, 169-178.

Churchill, S.W., Chu, H.H.S., (1975). Correlating equations for laminar and turbulent free convection from a vertical plate. Int. J. Heat Mass Transf. 18, 1323-1329.

Fossa, M., Ménézo, C., Leonardi, E., (2008). Experimental natural convection on vertical surfaces for building integrated photovoltaic (BIPV) applications. Exp. Therm. Fluid Sci. 32, 980-990.

Gaillard, L., Ménézo, C., Giroux, S., Pabiou, H., Le- 
Berre, R., (2014). Experimental Study of Thermal Response of PV Modules Integrated into Naturallyventilated Double Skin Facades. Energy Procedia 48, 1254-1261.

Kaiser, A.S., Zamora, B., Mazón, R., García, J.R., Vera, F., (2014). Experimental study of cooling BIPV modules by forced convection in the air channel. Appl. Energy 135, 88-97.

Kyritsis, A., Roman, E., Kalogirou, S.A., Nikoletatos, J., Agathokleous, R., Mathas, E., Tselepis, S., (2017). Households with Fibre Reinforced Composite BIPV modules in Southern Europe under Net Metering Scheme. Renew. Energy.

Lau, G.E., Sanvicente, E., Yeoh, G.H., Timchenko, V., Fossa, M., Ménézo, C., Giroux-Julien, S., (2012). Modelling of natural convection in vertical and tilted photovoltaic applications. Energy Build. 55, 810-822.

Lee, J.B., Park, J.W., Yoon, J.H., Baek, N.C., Kim, D.K., Shin, U.C., (2014). An empirical study of performance characteristics of BIPV (Building Integrated Photovoltaic) system for the realization of zero energy building. Energy 66, 25-34.

Mei, L., Infield, D., Eicker, U., Fux, V., (2003). Thermal modelling of a building with an integrated ventilated PV facade. Energy Build. 35, 605-617.

Ranjan, A., Dubey, S., Agarwal, B., Tiwari, G.N., (2008). Performance Analysis of an Existing BIPV System for Indian Climatic Conditions. Open Renew. Energy J. 1, $1-10$.

Roeleveld, D., Hailu, G., Fung, A.S., Naylor, D., Yang, T., Athienitis, A.K., (2015). Validation of Computational Fluid Dynamics (CFD) Model of a Building Integrated Photovoltaic/Thermal (BIPV/T) System. Energy Procedia 78, 1901-1906.

Sanjuan, C., Sánchez, M.N., Heras, M.D.R., Blanco, E., (2011a). Experimental analysis of natural convection in open joint ventilated façades with 2D PIV. Build. Environ. 46, 2314-2325.
Sanjuan, C., Suárez, M.J., Blanco, E., Heras, M.D.R., (2011b). Development and experimental validation of a simulation model for open joint ventilated façades. Energy Build. 43, 3446-3456.

Sanvicente, E., Giroux-Julien, S., Ménézo, C., Bouia, H., (2013). Transitional natural convection flow and heat transfer in an open channel. Int. J. Therm. Sci. 63, 87104.

Tkachenko, O.A., Timchenko, V., Giroux-Julien, S., Ménézo, C., Yeoh, G.H., Reizes, J.A., Sanvicente, E., Fossa, M., (2016). Numerical and experimental investigation of unsteady natural convection in a nonuniformly heated vertical open-ended channel. Int. J. Therm. Sci. 99, 9-25.

Wang, Y., Tian, W., Ren, J., Zhu, L., Wang, Q., (2006). Influence of a building's integrated-photovoltaics on heating and cooling loads. Appl. Energy 83, 9891003.

Yang, T., Athienitis, A.K., (2015). Performance Evaluation of Air-based Building Integrated Photovolta-ic/Thermal (BIPV/T) System with Multiple Inlets in a Cold Climate. Procedia Eng. 121, 2060-2067.

Yoo, S.-H., (2011). Simulation for an optimal application of BIPV through parameter variation. Sol. Energy 85, 1291-1301.

Zhang, R., Mirzaei, P.A., Carmeliet, J., (2017). Prediction of the surface temperature of building-integrated photovoltaics: Development of a high accuracy correlation using computational fluid dynamics. Sol. Energy 147, 151-163.

Zogou, O., Stapountzis, H., (2011). Experimental validation of an improved concept of building integrated photovoltaic panels. Renew. Energy 36, 3488-3498.

Zogou, O., Stapountzis, H., (2012). Flow and heat transfer inside a PV/T collector for building application. Appl. Energy 91, 103-115. 